\title{
EFL UNDERGRADUATES' JOURNAL ARTICLE PREFERENCES AND ACADEMIC READING STRATEGIES
}

\author{
Kasyfur Rahman \\ State Islamic University of Mataram \\ kasyfurrahman@uinmataram.ac.id
}

\begin{abstract}
This paper investigates the preferred criteria EFL undergraduates in an Indonesian University use for journal article selection and the strategies they employed for the reading of the articles. Five final year students were interviewed to collect pertinent data. Using semi-structured interview technique, the findings suggests that the main criterion for journal article selection is its similarity with their research topics. In addition to this, they also consider journal reputation as well as ease of access. Their preferences might be partially influenced by prior instruction from lecturers in relevant courses. In terms of reading strategies, they reported they did not read the whole article whilst focusing on certain structure such as abstract, findings, and conclusion. These strategies are mainly cognitive and overlook the metacognitive ones. Therefore, teachers are suggested to scaffold the reading journal articles to foster critical thinking and evaluation of the selected articles as well as metacognitive awareness to construct arguments from the texts.
\end{abstract}

Key words: Journal articles, preference, reading strategies, EFL undergraduates

\section{A. Introduction}

The availability and currency of scientific journal articles have brought about drastic change in the way undergraduates compose their thesis. Unlike what happened decades ago, when references used for thesis composition were mainly books, today's institutional policies commence higher education students to mainly take into account the use of journal articles as the main references along with predetermined standards such as limitation in terms of publication years, journal reputations, and the minimum numbers of journal articles that should be the references. Although these standards control students' motivation to read, individual preferences are also of considerable influence and interest to research. Recent study by Mizrachi (2015) unveiled that undergraduates prefer printed over electronic version of academic text even though this preference is also multifactorial in which accessibility, cost, and topic relevance to the course is also determinant. Mizrachi (2015) also notes that the ability to comprehend text, to synthesize ideas and to construct new concepts are 
of literacy development. Another research study by Alshargabi and Albeshari (2017) reports Yemeni higher education students' reading preferences. They revealed that students' motives for reading are different across levels. Level one students read for education, whilst their level two counterparts tend to read for pleasure.

Another prominent factor that highly influences one's reading comprehension is reading strategies. As part of reader characteristics, strategies determine how well one can comprehend a text. Meanwhile, it is inevitable to say that even for proficient readers, critically reading scientific texts are still daunting. Both psycholinguistic and metacognitive strategies are imperative in reading academic texts (Pae, Sevcik, Greenberg, \& Kim, 2016). In addition, since reading articles for final year undergraduates is intended to construct arguments from academic text, it is imperative to make use of appropriate strategies. More importantly, as suggested by Hermida (2009), reading academic text necessitates deep approach to reading.

In the context of undergraduate EFL courses, students read journal articles at least for two reasons. First, they are commenced to read peer-reviewed journal in order to fulfill course instruction or task assigned by lecturers. Second, the reading of journal articles has been compulsory for final year undergraduates in preparation for thesis writing. Yet, a question raises whether they really critically read these journal articles, or simply to fulfill the requirements set by the higher education institutions. Therefore, this paper attempts to investigate what criteria EFL undergraduates use when selecting journal articles, how these criteria match their preferences as well as kinds of strategy they employ to comprehend this highly complex genre.

\section{B. Literature Review}

\section{Selecting journal articles for references}

For a novice writer, choosing the right journal articles can be a daunting task. In fact, the most fundamental skill necessary for research process is the ability to locate published sources on a topic (Rau, 2004). In addition to the relevance to research topic, there are myriad of criteria that can help one search for right journal articles. First, one should be aware of the types of journal and orientation. Renandya (2014) mentions two types of Applied linguistics and TESOL journals based on their orientation: teaching-oriented journals and research-oriented journals. For scientific paper or thesis, the most appropriate types of journals would be research-oriented journals. Meanwhile, with the advent of internet and public access, students are now offered plethora of choices in the online spheres. Mizrachi (2010) reports that most of her research participants started they research projects on public internet sources. Meanwhile, choosing the right journal articles for references and carefully review them would help avoid useless duplication effort as well as advocates research topics and methods (Rau, 2004). 


\section{Reading comprehension strategies}

Strategies can be defined as any actions carried out by individuals to attain goals they set. In terms of reading comprehension, a variety of views on the types of strategies have been coloring the scholarship of reading epistemology. Generally, however, the strategies might be categorized into cognitive and metacognitive strategies. The cognitive one, as suggested by Sani, Wan Chik, Awg Nik, and Raslee (2011), assists students to construct meaning from the text. This is generally carried out through either top-down or bottom-up approach. The top down approach makes use one's background knowledge, prediction, skimming, and obtaining the gist of a text, whilst the bottom-up approach makes use of one's understanding from sentence levels. On the other hand, metacognitive strategies enable students to check or monitor whether cognitive strategies undertaken is successful or not. In other words, metacognition is the awareness and control over our own cognitive processes (Karbalaei, 2010). Although has been long overlooked, metacognitive strategy plays pivotal role in one's success in reading comprehension. Ahmadi, Ismail, and Abdullah (2013) suggest that unlike cognitive strategy, metacognitive strategy allow readers to be aware of what to do when they encounter difficulties in learning. Thus, they will employ strategies to overcome the problems. Among metacognitive strategies are knowledge and regulatory skills. The former refers to know 'what, 'how', and 'when \& why' to apply cognitive actions to accomplish a task. On the other hand, regulatory skills involve planning, monitoring, and evaluating whether cognitive strategies employed are successful for textual comprehension.

\section{Method}

The research presented in this paper employs narrative approach to research. Narrative research or inquiry focuses on the stories told by people on their life experiences and how they figure out these experiences (Barkhuizen, 2018). In narrative research on language learning context, learners tell about their experience with regard to learning and using languages (Barkhuizen, 2014). The subjects' story is retold in academic and scientific approach by the author. Nowadays, storytelling has been increasingly used to depict how individuals experience life. In order to collect data, semi structured interview was administered to five final year students of TESOL study program in a local Indonesian university, namely Ibrahim, Rizal, Guntur, Ba'iyah, and Sofyan (Pseudonyms). The interview covers two main aspects of their experience: their preferences when selecting journal articles to read and strategies they used for text comprehension. The data collected were analyzed using thematic analysis in which transcript of interview are presented and discussed based on two broad themes: i.e. preferences and strategies. 


\section{Findings and Discussion}

This section elaborates the extent to which students experience the selection of mostly appropriate journal articles they need along with the strategies they employed to comprehend the journal articles they selected.

\section{Criteria for Journal article selection \\ a. Ibrahim's Preference}

"The main consideration is the title of our thesis proposal; therefore, we search for articles that match it although it is often difficult to find articles that matches our research topic, we still can find few although not quite relevant. We also consider the DOI and whether the article is listed in scientific portals like Sciencedirect"

Ibrahim demonstrates that the choice of journal articles he searched as references is determined by the relevance to his research title. As Rau (2004) suggests, locating texts mostly relevant to our topic is a fundamental skill. However, as indicated by Ibrahim, there are difficulties to access the intended journal articles. In addition, the selection is based on the DOI (Digital Object Identifier) which is the link to the original article for security reasons and the article suppliers such as Sciencedirect. Having both DOI and reliable sources like Sciencedirect allows academic writers to persuade the readers that their references are valid and accurate. This is in line with Mizrachi's (2010) suggestion in that the significance of being smart consumer of information through critical thinking skills and strategies of evaluating the sources should be stressed.

\section{b. Rizal's Preference}

"To come up with selected articles, firstly I read the abstracts, then determine whether the ideas are closely related to mine. I also consider reliable websites that provide scientific journal articles. Take for example, I do not use Wikipedia as my reference since it is editable by anyone".

Rizal's decision to select journal articles based on the abstracts reflect careful selection of articles to read. Literature review itself is the quest and reading for all published articles on a given questions and topic with certain limitation (Rau, 2004). What Rizal attempted to do also demonstrates the avoidance of unreliable websites such as Wikipedia as the references. This also occurs in Mizrachi's (2010) study in which her participants were cautioned by their instructor that Wikipedia was not a considerable resource, but a good start

\section{c. Guntur's Preference}

"Usually I read the abstract first then go to the conclusion to determine whether these articles worth or not as my references. In other words, they have to match my research topic. I also prefer sciencedirect since most of my references are based on it" 
Similar to Rizal's decision making, Guntur demonstrates further milestone to determine which articles he should read. He does not only focus on the abstract but also on the conclusion section to come to conclusion drawing whether the article is worth referencing or not. In addition, his choice to access Sciencedirect reflects highly selective preferences as Sciencedirect is among top online libraries that provides top-notch journals under Elsevier, Ltd company. Mizrachi (2010) points out that instructor and librarians should encourage students to critically think and evaluate the legitimacy of the internet sources they seek.

\section{d. Ba'iyah's preference}

"The articles I want to read must have similar title to my thesis proposal. The articles can be from international journal or local ones as long as they have valid online version"

In contrast to other students, Ba'iyah is softer and more tolerant to local journals. This decision should be appreciated since the thesis undertaken by Ba'iyah is written for intended audience not for expert readers (Hamilton, 2018). Several research projects in Indonesian context which should be the most relevant to her research context, are scanty in international journals, but exist in loads of local journals. However, the same issue here is the validity and reliability of the sources.

\section{e. Sofyan's Preference}

"I prefer reputable and international journals, especially those which are accredited. For non-accredited journals, I do not use them as references, I just access them as a measure whether this is good or bad".

Sofyan's preference shows that he accesses any kinds of journals for reading purpose and not for referencing. Only reputable and international journals are cited in his references. This decision might come from external factor, i.e, institution or supervisors, who put high standards for undergraduate thesis. Hamilton (2018) notes that lecturers who finished their postgraduate study unconsciously set the standards they used during their studies for undergraduates.

\section{Reading strategy}

\section{a. Ibrahim's strategy}

"The first way of reading is skimming, reading a bit, knowing the function and the meaning. Sometimes we use dictionary to look up difficult words, and when it turns out to be incomprehensible, we use translation tool, although quite rarely. We do not read the whole article; we focus several parts. The first is abstract because it summarizes the content of the article and also the conclusion".

Ibrahim's narration demonstrates cognitive strategies through skimming and a focus on understanding at sentence level. Nonetheless, as reported by Hermida (2009) most undergraduates tend to use surface approach than deep approach to reading. 
Interestingly, he uses translation tool when encountering difficult words. Translation can be used as a tool to learn new vocabulary (Mahmoud, 2006). In addition, there is also a selection of certain part of articles, such as abstract and conclusion. Durbin (2009) states that abstract is the most important part to examine, second to the title. The abstract is the miniature of the research since it entails the aims, methods, and findings therefore illuminates how the entire article would be like.

\section{b. Rizal's Strategies}

"I do not read the whole articles, I read some starting from the abstract as it tells us the overview of the article and the introduction section as well but not that detail. Once I understand what is in the introduction section, I go to the method section and the results and discussion, but not that detail again. Sometimes I used dictionary to help myself understand words' meaning."

To come into understanding, Rizal attempted to skim parts of articles which is a cognitive strategy. However, unlike his peers, Rizal's attempt for textual comprehension also takes into account the introduction section. The introduction section serves to inform readers about the topic under study and serves to illuminate about the background of the research. Using dictionary to assist understanding, furthermore, helps readers to figure out unfamiliar words. Ma \& Cheon (2018) unveiled in their research that dictionary use for vocabulary learning and reading comprehension brought about substantial improvement. Therefore, using dictionary helps him figure out his disadvantage of shallow breadth of vocabulary.

\section{c. Guntur's strategy}

"I did not read the whole articles, and I just tried to find out the points, for example, the problems in speaking instruction, then I would try to find the points related to this topic. I also read only the abstract, findings, and conclusions and to do so, I need only ten minutes in average. Just by reading the title of the article, we can predict the contents. I also focus on the key words in the findings."

Finding the points or main ideas in journal articles, as narrated by Guntur is an epitome of cognitive strategy for reading comprehension. Seen from the time he spent for reading several parts of the articles, it seems that Guntur's attempt to gain understanding of the text is through skimming. In terms of selecting the most appropriate journals articles that match particular topics this strategy is sufficient, yet to evaluate and construct arguments from the articles, holistic understanding is required to foster critical thinking about where the authors of the articles stand and avoiding bias to the authors' stance.

\section{d. Ba'iyah's strategy}

"My main strategy is to figure out the key words so we can know the outline of the ideas in the articles. I also use dictionary to translate difficult words. I would read only the main 
points. For example, I read the title, the abstract since we can know the overall content of the article, the findings and conclusions. To read the abstracts I just need two hours, and to read the other sections I use translation. I could not understand the whole article, but I have to make sure to totally understand the abstracts. I do not necessarily need to understand the rest".

In Ba'iyah's case, finding key words is still the mostly used strategy although she needs time to comprehend the articles. Selective reading is also another strategy she used which is similar to her peers. For Ba'iyah, understanding the abstract is of paramount importance, while understanding other parts is not necessary. For preliminary reading this might be true. However, it should be noted that understanding the whole article is necessary to build arguments in academic writing.

\section{e. Sofyan's strategy}

"Reading the whole article is a waste of time, so I only focus on some important parts including the title and abstract, findings, and the conclusions. Reading the abstract only takes 2 hours in average, but reading those parts need around two days and I have to read the translations. Reading the abstract helps figure out the overall content of the articles. I read the articles using $5 \mathrm{~W}+1 \mathrm{H}^{\prime \prime}$

Sofyan demonstrates that he selected certain parts that are relevant to his preferences. Nonetheless, reading all parts of the retrieved articles might be timeconsuming, yet understanding selected papers is key to the evaluation and construction of arguments. Nonetheless, he also makes use of translation to help him out with comprehension of the text. Like Ba'iyah, Sofyan thought the reading of the abstract is the central key to understanding the whole text. However, in this respect his strategy is more systematic in which he uses $5 \mathrm{~W}+1 \mathrm{H}$.

While, students' diversity in preferences for searching literature and reading strategies should be appreciated (Mizrachi, 2010), it should be clear that the students need more models of searching the most relevant references although they have been trained to read critically through limited exposure to academic text through critical reading course. Take for example, locating the most recent and relevant sources by examining an article's references as a starting point. Another possible way is to identify journals that specialize in the field of the students' area of expertise. The last, they may consider reading review article, a type of article that synthesizes recent findings on certain topics. This kind of article provides countless references that are relevant to the topic it addresses.

\section{E. Conclusion}

While most of the students' narrations demonstrate similar journal article preferences and reading strategies. This phenomenon is probably due to the teaching of higher education instructor or lecturers who model and encourage them to do so. Nonetheless, several issues remain under questions. Since searching for literature is 
a formidable task, the students should be triggered to be more critical and evaluative in determining the right articles they have to access and read. In addition to this, they have to be more aware of effective ways of searching and linking the sources with their research topic. In the case of reading strategies, most students show heavy tendencies of cognitive strategies while lacking the metacognitive ones. Therefore, this paper suggests the teaching of metacognitive strategies for students and scaffolding academic reading for them.

\section{References}

Al-Shargabi, E., \& Al-Beshari, A. (2017). Reading Preferences of Yemeni Undergraduate EFL Learners. Journal of Social Studies, 8(2): 128-140. https: / / doi.org/ 10.20428/ JSS.23.2.6

Mizrachi, Diane. (2010). Undergraduates' academic information and library behaviors: preliminary results. Reference Services Review, 38 (4): 571 - 580. http: / / dx.doi.org/10.1108/00907321011090737

. (2015). Undergraduates' Academic Reading Format Preferences and Behaviors. The Journal of Academic Librarianship. 41(3):301-311 doi: 101016/j. acalib.2015.03.009.

Durbin. C.G. (2009). How to read a scientific research paper. Respiratory Care, 54(10): 1366-1371

Barkhuizen, G. (2014). Narrative research in language teaching and learning. Language Teaching, 47: 450-466. doi:10.1017/S0261444814000172

(2018). Research in English for speakers of other languages. The TESOL Encyclopedia of English Language Teaching. Edited by John I. Liontas (Project Editor: Margo DelliCarpini; Volume Editor: Ali Shehadeh). Pp 1-7. DOI: 10.1002/9781118784235.eelt0227

Hamilton, J. (2018). Academic reading requirements for commencing HE students - A professional reflection on whether peer reviewed journals are the right place to start. A Practice Report. Student Success, 9(2), 73-79. doi: 10.5204/ssj.v9i2.408

Hermida, J. (2009). The importance of teaching academic reading skills in first-year university courses. The International Journal of Research and Review. Volume 3: 20-31

Ma, J.H, \& Cheon, H.J. (2018). An Experimental study of dictionary use on vocabulary learning and reading comprehension in different task conditions. International Journal of Lexicography, 31(1): 1-24

Mahmoud, A. (2006). Translation and foreign language reading comprehension: A neglected didactic procedure. English Teaching Forum, 4: 28-40 
Ahmadi, Hairul, M.R., Ismail1, N. \& Abdullah, M.K.K. (2013). The Importance of Metacognitive Reading Strategy Awareness in Reading Comprehension. English Language Teaching, 6(10): 235-244. doi:10.5539/ elt.v6n10p235

Pae, Hye K., Rose A. Sevcik, Daphne Greenberg, and Sun-A Kim. (2016). Relationships among metacognitive skills, listening, and academic reading in English as a foreign language. Linguistic Research 33 (Special Edition), 1-27

Rau, J.L. 2004. Searching the literature and selecting the right references. Respiratory Care, 49(10): 1242-1245

Renandya, W. A. (2014). Choosing the right international journal in TESOL and AppliedLinguistics. EnglishLanguage Teaching WorldOnline(ELTWO), 6:1-17. Retrieved fromhttp: / blog.nus.edu.sg/ eltwo/2014/06/18/ choosing-the-right-internationaljournal-in-tesoland-applied-linguistics-2/

Sani, B.B, Wan Chik, M. N., Nik, Y.A., \& Raslee, N.A. (2011). The Reading Motivation and Reading Strategies Used by Under graduates in University Teknologi MARA Dungun, Terengganu. Journal of Language Teaching and Research, 2 (1):32-39. doi: $10.4304 /$ jltr.2.1.32-39 